\title{
Energy Expenditure and Deposition of Breast-Fed and Formula-Fed Infants during Early Infancy ${ }^{1}$
}

\author{
NANCY F. BUTTE, WILLIAM W. WONG, LAURA FERLIC, E. O'BRIAN SMITH, \\ PETER D. KLEIN, AND CUTBERTO GARZA ${ }^{2}$ \\ USDA/ARS Children's Nutrition Research Center, Department of Pediatrics, Baylor College of Medicine and \\ Texas Children's Hospital, Houston, Texas 77030
}

\begin{abstract}
The energy intake, expenditure, and deposition of 40 breast-fed and formula-fed infants were investigated at 1 and 4 mo of age to explore possible differences in energy utilization between feeding groups. Energy intake was calculated from 5-d test-weighing records or pre- and postweighing of formula bottles, in combination with bomb calorimetry of the milks. Total daily energy expenditure (TDEE) was determined by the doubly labeled water method. Sleeping metabolic rate (SMR) and minimal observable energy expenditure were measured by indirect calorimetry. Activity was estimated as the difference between TDEE and SMR. Energy deposition was estimated from dietary intake and TDEE. Energy intakes were significantly higher for the formula-fed than breast-fed infants at $1 \mathrm{mo}(118 \pm 17$ versus $101 \pm 16 \mathrm{kcal} / \mathrm{kg} / \mathrm{d})$ and $4 \mathrm{mo}$ $(87 \pm 11$ versus $72 \pm 9 \mathrm{kcal} / \mathrm{kg} / \mathrm{d})(p<0.001)$. TDEE averaged $67 \pm 8$ and $64 \pm 7 \mathrm{kcal} / \mathrm{kg} / \mathrm{d}$ at $1 \mathrm{mo}$ and $73 \pm 9$ and $64 \pm 8 \mathrm{kcal} / \mathrm{kg} / \mathrm{d}$ at $4 \mathrm{mo}$ for the formula-fed and breast-fed infants, respectively, and differed between feeding groups $(p<0.04)$. SMR and minimal observable energy expenditure ( $\mathrm{kcal} / \mathrm{min}$ ) were higher among the formula-fed infants at 1 and 4 mo $(p<0.005)$. The energy available for activity and the thermic effect of feeding did not differ between feeding groups. Rates of weight gain $(\mathrm{g} /$ d) and energy deposition ( $\mathrm{kcal} / \mathrm{kg} / \mathrm{d}$ ) tended to be greater among the formula-fed infants at 1 and $4 \mathrm{mo}(p<0.06)$. Differences in weight gain, energy deposition, SMR, minimal observable energy expenditure, and TDEE partially accounted for the discrepancy in energy intake observed between breast-fed and formula-fed infants. The response to the varying levels of energy intake in infancy appear to be mediated through growth and basal-energy-requiring processes, but not through physical activity. (Pediatr Res 28: 631-640, 1990)
\end{abstract}

\section{Abbreviations}

TDEE, total daily energy expenditure SMR, sleeping metabolic rate MOEE, minimal observable energy expenditure TEF, thermic effect of feeding

Received December 18, 1989; accepted August 3, 1990

Correspondence and reprint requests: Nancy F. Butte, Ph.D., USDA/ARS Children's Nutrition Research Center, 1100 Bates, Room 8068, Houston, TX 77030.

'This work is a publication of the USDA/ARS Children's Nutrition Research Center, Department of Pediatrics, Baylor College of Medicine and Texas Children's Hospital, Houston, TX. This projects has been funded in part with federal funds from the U.S. Department of Agriculture, Agriculture Research Service under Cooperative Agreement number 58-7MN1-6-100. The contents of this publication do not necessarily reflect the views or policies of the U.S. Department of Agriculture, nor does mention of trade names, commercial products, or organizations imply endorsement by the U.S. Government.

${ }^{2}$ Present address: 127 Savage Hall, Division of Nutritional Science, Cornell University, Ithaca, NY 14853.

\begin{abstract}
$\mathrm{N}_{\mathrm{O}}$, average ${ }^{18} \mathrm{O}$ dilution space
$\mathrm{N}_{\mathrm{H}}$, average ${ }^{2} \mathrm{H}$ dilution space

$\mathrm{k}_{\mathrm{O}}$, fractional turnover rate of ${ }^{18} \mathrm{O}$

$\mathbf{k}_{\mathrm{H}}$, fractional turnover rate of ${ }^{2} \mathbf{H}$

IWL, insensible water loss

$\mathrm{CV}$, coefficient of variation
\end{abstract}

NCHS, National Center for Health Statistics

EE02, postprandial energy expenditure at 0 to $2 \mathrm{~h}$

EE23, postprandial energy expenditure at 2 to $3 \mathrm{~h}$

EE34, postprandial energy expenditure at 3 to $4 \mathrm{~h}$

EE03, postprandial energy expenditure at 0 to $3 \mathrm{~h}$

EE04, postprandial energy expenditure at 0 to $4 \mathrm{~h}$

Adaptations to varying levels of energy intake may affect an infant's body mass or composition, basal metabolism, activity, or thermogenesis. Although the response to severe energy restriction during infancy is well documented (1), the response to seemingly adequate but different levels of energy intake is not well understood. Energy intakes of breast-fed and formula-fed infants have been shown to differ after the first few months of life (2-4). Differing energy intakes between feeding groups imply that energy absorption, expenditure, and (or) deposition between groups also differ. In a previous study (3), we reported a $27 \%$ difference in energy intake between breast-fed and formula-fed infants at 4 mo of age, but did not observe statistically significant differences in length, body weight, or weight gain. Nor were anticipated differences in selected components of energy expenditure detected; SMR, TEF, and postprandial energy expenditure did not differ between feeding groups. Rates of MOEE were higher among the formula-fed infants, but the increment was insufficient to account for the differences in energy intake. Rates of weight gain tended to be greater among the 4-mo-old formulafed than breast-fed infants $(p<0.10)$, but the discrepancy in energy intake was too large to be explained solely on the basis of growth velocity. Because these findings suggested that differences in body composition and energy expended on activity might account for the putative differences in energy utilization, we undertook our study to measure TDEE and total body water.

Recent reports $(5-10)$ have shown that the doubly labeled water method for the noninvasive determination of TDEE can be applied in infants to complement indirect calorimetric measurements of SMR. In our present study, we combined the doubly labeled water method with conventional indirect calorimetry to explore possible differences in energy utilization between breastfed and formula-fed infants.

\section{MATERIALS AND METHODS}

Study design. A cross-sectional study was designed to compare energy intake, growth, and energy expenditure of 40 breast-fed 
and formula-fed infants at 1 and 4 mo of age. The sample was independent from the sample described in reference 3. Two infants who did not complete the study because of family illness and maternal failure to comply with study procedures were replaced with new subjects. Infants were required to be healthy, the result of term delivery, of appropriate size for gestational age, and above the 10th NCHS weight-for-age percentile (11) at birth. Infants recruited at 1 mo of age were to be fed either human milk or formula exclusively. Infants recruited at 4 mo also were to be fed either human milk or formula exclusively; their diets, however, could be supplemented, not to exceed $15 \%$ of energy intake. For screening purposes, infant intake was assessed by maternal recall. The formulas used were Enfamil (Mead Johnson and Company, Evansville, IN) and Similac (Ross Laboratories, Columbus, $\mathrm{OH}$ ) with and without supplemental iron. Participating mothers were required to be healthy, aged 18 to $35 \mathrm{y}$, parity 3 or less, and to be on no long-term medications.

Approximately $1 \mathrm{wk}$ before the mother and infant were admitted to the Clinical Research Center at Texas Children's Hospital, a breast-feeding consultant/health communicator from the Children's Nutrition Research Center visited the home to obtain a health and feeding history of the infant. A 1-mo supply of readyto-feed formula originating from one factory was delivered to the formula-fed infants to minimize shifts in natural abundances of ${ }^{18} \mathrm{O}$ and ${ }^{2} \mathrm{H}$ in body water (12). We found that formulas manufactured in six different geographic locations varied in the enrichment $(\Delta / \mathrm{mil})$ of ${ }^{18} \mathrm{O}(-7.04 \pm 1.09)$ and ${ }^{2} \mathrm{H}(-36.86 \pm$ $8.87)$. Electric breast pumps were delivered to the breast-feeding mothers who were trained to express and freeze a daily aliquot of human milk in preparation for the 24 -h milk collection.

The mother and infant were admitted to the Clinical Research Center for approximately $24 \mathrm{~h}$, at which time the infant underwent the following procedures: routine physical examination, anthropometric measurements, assessment of food intake, indirect calorimetry, measurement of IWL, and initiation of the doubly labeled water measurement. Follow-up procedures conducted in homes of subjects over a 14-d period included: daily urine sampling, 5-d assessment of food intake, and (for the breastfeeding pair) a 24-h milk collection. Maternal or infant illnesses were avoided in the scheduling of the latter two procedures. Anthropometric measurements were repeated at the end of the study (d 14).

The study was approved by the Institutional Human Experimentation Committees of Baylor College of Medicine and Texas Children's Hospital. Written, informed parental consent was obtained for all studies.

Anthropometry. Weights of nude infants were obtained on electronic, integrating scales (model 3862MP, Sartorius Göttingen, FRG) at least $1 \mathrm{~h}$ after feeding. Weight gain was calculated as the difference between weights measured on $\mathrm{d} 1$ and 14 . Infant length was measured on a recumbent infant board on $\mathrm{d} 1$ and 14.

Clinical assessment. Infants were examined by the attending pediatrician. Routine vital signs including rectal temperature, blood pressure, and pulse were taken twice daily by the nursing staff.

Food intake. The intake of human milk during the $24 \mathrm{~h}$ in the Clinical Research Center and for $5 \mathrm{~d}$ at home was assessed by test-weighing (13). Infant weights were measured before and after each feeding on Sartorius scales and were not corrected for IWL during the period of feeding.

Formula intake was determined from pre- and postweights of 4-fl-oz $(118 \mathrm{~mL})$ ready-to-feed bottles. Preweighed towels were provided to recover any formula losses.

Preweighed jars/bottles of baby foods, juices and water, and preweighed towels were supplied for those infants who received supplements for the entire 14-d period. The type of supplement and time of feeding were recorded by the mothers. Used jars/ bottles and towels were returned to the laboratory and reweighed so that the amount consumed by the infant could be recorded. Intakes were standardized over $24 \mathrm{~h}$.

Twenty-four- $h$ milk collection. The $24-\mathrm{h}$ milk collection was conducted on a separate day after the 5-d test weighing. Mothers were instructed to breast-feed their infants according to their usual pattern. At each feeding over a 24 -h period, the infant nursed from one breast, and milk was expressed from the other breast with an electric breast pump (Egnell, Inc., Cary, IL). Alternate breasts were used for feeding and pumping at successive feeds. Human milk that had been collected and frozen in advance was used to supplement feedings. Milk samples were refrigerated in sterile, polypropylene bottles until the next day, at which time they were delivered to the laboratory where they were pooled to compose 24-h samples.

Biochemical analysis. The energy content of human milk, formula, and supplemental foods was determined in an adiabatic bomb calorimeter (Parr Instruments, Moline, IL). Nitrogen was analyzed by the Kjeldahl method before and after trichloroacetic acid precipitation of protein (Kjeltec Auto Analyzer 1030, Tecator, Hoganas, Sweden). Nonprotein nitrogen was determined on the supernatant, and protein nitrogen was estimated from the difference between total nitrogen and nonprotein nitrogen. Protein nitrogen was converted to protein using the factor 6.25 . Lactose was determined using an automatic analyzer (YSI, model 127, Yellow Springs, OH). Fat was determined by the Jeejeebhoy method (14).

Indirect calorimetry. Our indirect calorimeter for infants has been described in detail elsewhere (3). Briefly, the components of this open circuit system are a $105-\mathrm{L}$ Plexiglas chamber, a turbine flow system (VMM-2 Ventilation Measurement Module, Alpha Technologies, Inc., Laguna Hills, CA), a dual cell oxygen analyzer (AMTEK N-37/S-3AII, Ametek, Inc. Thermox Instruments Division, Pittsburgh, PA), two carbon dioxide analyzers (AMTEK P61B/CD3A), and a microcomputer (Hewlett Packard 85B, Hewlett-Packard Co., Palo Alto, CA). The equations used to calculate $\mathrm{O}_{2}$ consumption and $\mathrm{CO}_{2}$ production were described by Jequier (15). The Weir equation (16), necessary when urinary nitrogen is not measured, was used to calculate energy expenditure.

Continuous measurement of energy expenditure for 4 consecutive postprandial $h$ was planned at the infant's usual evening sleeptime. Infants were diapered and lightly clothed in hospital gowns or pajamas. Infants were fed human milk or formula ad libitum, coaxed to sleep, and then placed in the calorimeter. The mean and SD of the minute-to-minute measurements of oxygen consumption, carbon dioxide production, RQ, and energy expenditure were computed for the postprandial intervals 0 to $2 \mathrm{~h}$, 2 to $3 \mathrm{~h}$, and 3 to $4 \mathrm{~h}$. EE02, EE23, EE34, EE03, and EE04 represent the mean $(\mathrm{kcal} / \mathrm{min})$ postprandial energy expenditures at 0 to $2 \mathrm{~h}, 2$ to $3 \mathrm{~h}, 3$ to $4 \mathrm{~h}, 0$ to $3 \mathrm{~h}$, and 0 to $4 \mathrm{~h}$ from the end of the feeding, respectively. The SMR was defined operationally as either EE23 or EE34, whichever was smaller and (or) available. The minimal 5-min interval observed during the SMR was identified and designated as MOEE.

Because the infants were not fasted, the TEF was calculated relative to EE34, SMR, and MOEE. The TEF was expressed as a percentage rise in energy expenditure for the postprandial period 0 to $3 \mathrm{~h}$ according to the following equations:

$$
\begin{aligned}
\text { TEF:EE34 } & =\frac{\text { EE03 }- \text { EE34 }}{\text { EE34 }} \times 100 \\
\text { TEF:SMR } & =\frac{\text { EE03 }- \text { SMR }}{\text { SMR }} \times 100 \\
\text { TEF }: \text { MOEE } & =\frac{\text { EE03 }- \text { MOEE }}{\text { MOEE }} \times 100
\end{aligned}
$$

$I W L$. For the measurement of IWL, an open bassinet was attached to an electronic, integrating balance (Sartorius 3862 
MP8). Infants were clothed in preweighed diapers and light, cotton hospital gowns for the test; urine bags were affixed to the infants to prevent evaporation of urine. Cotton sheets on the bassinet mattress were preweighed. After the infants had fallen asleep, they were placed into the bassinet; their weights were recorded at 5-min intervals until they awakened. Diapers, gowns, and sheets were reweighed at the end of the measurement.

Doubly labeled water method. A solution of ${ }^{18} \mathrm{O}$-labeled water at 93.6 atom percent ${ }^{18} \mathrm{O}$ and ${ }^{2} \mathrm{H}_{2} \mathrm{O}$ at 99.8 atom percent ${ }^{2} \mathrm{H}$ was sterilized by passage through an Acrodisc filter (Gelman, Ann Arbor, MI); sterilization and lack of pyrogenicity were verified by standard culture plate techniques and limulus amebocyte lysate (Pyrogent, Mallinckrodt, Inc., St. Louis, MO), respectively. The dose of ${ }^{2} \mathrm{H}_{2}{ }^{18} \mathrm{O}$ was equivalent to $300 \mathrm{mg}{ }^{18} \mathrm{O}$ and $200 \mathrm{mg}$ ${ }^{2} \mathrm{H}_{2} \mathrm{O} / \mathrm{kg}$ body weight.

A baseline urine sample was collected from each infant before oral administration of ${ }^{2} \mathrm{H}_{2}{ }^{18} \mathrm{O}$. Urine samples were collected at 6 $\mathrm{h}$ postdose and daily thereafter for $14 \mathrm{~d}$. Samples were collected in sterile, pediatric specimen bags (U-Bag, Hollister, Inc., Kurtsville, MO), transferred with a syringe to o-ring sealed sample vials, and then frozen at $-20^{\circ} \mathrm{C}$. Mothers were trained by the Clinical Research Center nurse and continued the collections at home. The time of collection was recorded.

Urine samples were analyzed for ${ }^{2} \mathrm{H}$ and ${ }^{18} \mathrm{O}$ enrichment using a Finnigan Delta-E gas-isotope-ratio mass spectrometer (Finnigan MAT, San Jose, CA) and a VG-SIRA 12/ISOPREP-18 mass spectrometer system (Isotech Limited, Middlewich, Cheshire, UK), respectively, as described by Wong et al. (17).

The Simulation, Analysis, and Modeling (SAAM version 29, $\mathrm{NIH}$, Bethesda, MD) computer program was used to fit curves for the monoexponential decay of ${ }^{18} \mathrm{O}$ and ${ }^{2} \mathrm{H}$ in the urine samples. To assure isotope equilibration, the 6 -h postdose urine sample was excluded from analysis. To minimize errors introduced by the rapid depletion of ${ }^{18} \mathrm{O}$ in urine and shifts in baseline isotopic enrichments, the single compartmental analysis was limited to the isotopic data representing three biologic half-lives of ${ }^{18} \mathrm{O}$ of each infant.

The initial isotope dilution spaces $\left(\mathrm{N}_{1}\right)$ of ${ }^{18} \mathrm{O}$ and ${ }^{2} \mathrm{H}$ were calculated from the isotopic enrichments of ${ }^{18} \mathrm{O}$ and ${ }^{2} \mathrm{H}$ as

$$
\mathrm{N}_{1}(\mathrm{~g})=\frac{\mathrm{d} \cdot \mathrm{APE} \cdot 18.02}{\mathrm{MW} \cdot 100 \cdot \delta^{\prime} \cdot \mathrm{R}_{\mathrm{std}}}
$$

where $\mathrm{d}$ is the amount of ${ }^{18} \mathrm{O}$-labeled water or ${ }^{2} \mathrm{H}_{2} \mathrm{O}(\mathrm{g})$; MW is the molecular weight of the labeled water $(\mathrm{g} / \mathrm{mol})$; atom percent excess (APE) was calculated from the isotopic enrichments measured by isotope-ratio mass spectrometry after gravimetric dilution of the ${ }^{2} \mathrm{H}_{2}{ }^{18} \mathrm{O}$ solution; $\delta^{\prime}$ is the intercept or zero-time enrichment of ${ }^{18} \mathrm{O}$ or ${ }^{2} \mathrm{H}$ over baseline; and $\mathrm{R}_{\text {std }}$ is the reference standard ${ }^{18} \mathrm{O} /{ }^{16} \mathrm{O}$ or ${ }^{2} \mathrm{H} /{ }^{1} \mathrm{H}$ ratio of Vienna-standard mean ocean water which has a value of 0.0020052 (18) or 0.00015595 (19), respectively.

$N_{O}$ or $N_{H}$ was calculated (5) as

$$
\mathrm{N}_{\mathrm{O}} \text { or } \mathrm{N}_{\mathrm{H}}(\mathrm{g})=\left(\mathrm{N}_{1}-\mathrm{N}_{2}\right) / \ln \left(\mathrm{N}_{1} / \mathrm{N}_{2}\right)
$$

where $N_{1}$ and $N_{2}$ are the dilution spaces at time zero and at the end of the period ( $t$, in days) representing three biologic halflives of ${ }^{18} \mathrm{O} . \mathrm{N}_{2}$ was estimated from weight gain under the assumption that dilution spaces changed in proportion to weight during the course of study.

Carbon dioxide production rates $\left(\mathrm{r}_{\mathrm{CO}_{2}}\right)(5)$ were calculated as

$$
\begin{aligned}
\mathrm{r}_{\mathrm{CO}_{2}}(\mathrm{~g} / \mathrm{d})= & 0.9625 \cdot\left[\left(\mathrm{N}_{\mathrm{O}} \cdot \mathrm{k}_{\mathrm{O}}-\mathrm{Q}_{\mathrm{O}}\right)\right. \\
& \left.-\left(\mathrm{N}_{\mathrm{H}} \cdot \mathrm{k}_{\mathrm{H}}-\mathrm{Q}_{\mathrm{H}}\right)(1-0.01 \cdot \mathrm{X}) /(1-0.055 \cdot \mathrm{X})\right]
\end{aligned}
$$

where $\mathrm{k}_{\mathrm{O}}$ and $\mathrm{k}_{\mathrm{H}}$ are the fractional turnover rates of ${ }^{18} \mathrm{O}$ and ${ }^{2} \mathrm{H}$, respectively. $Q_{O}$ and $Q_{H}(g / d)$ are the daily changes in ${ }^{18} \mathrm{O}$ and ${ }^{2} \mathrm{H}$ dilution spaces, i.e. $\left(\mathrm{N}_{1}-\mathrm{N}_{2}\right) / \mathrm{t}$. The fraction of IWL relative to total water output is denoted by $\mathrm{X}$. In vivo isotope fractiona- tion factors of $0.945\left(f_{1}\right), 0.990\left(f_{2}\right)$, and $1.039\left(f_{3}\right)$, measured at $37^{\circ} \mathrm{C}$, were used (20).

Oxygen consumption $\left(\mathrm{r}_{2}\right)$ was calculated from $\mathrm{r}_{\mathrm{CO}_{2}}$ and the mean RQ of the interval EE04, or EE03, if the former were not available. The Weir equation (16) was used to convert $\mathrm{r}_{\mathrm{CO}_{2}}$ and $\mathrm{r}_{\mathrm{O}_{2}}$ to TDEE.

$$
\operatorname{TDEE}(\mathrm{kcal} / \mathrm{d})=22.4 \cdot\left(1.106 \cdot \mathrm{r}_{\mathrm{CO}_{2}}+3.941 \cdot \mathrm{r}_{\mathrm{O}_{2}}\right) \text {. }
$$

The energy available for activity was estimated from the difference between TDEE and SMR. Energy deposition was calculated from the difference between metabolizable energy intake, taken to be $92 \%$ of gross energy intake (21), and TDEE.

Statistical analysis. Analysis of variance (SPSS-X) (22) was used to analyze the biographical, intake, anthropometric, and energy expenditure data. Grouping factors were feeding mode (human milk or formula), sex, and age (1 mo or $4 \mathrm{mo}$ ). Reference to a significant feeding effect implies a significant difference at both 1 and 4 mo of age or for both male and female infants, unless a significant interaction was encountered. In that case, the feeding effect was tested and presented separately by age or sex. Analysis of covariance for repeated measures (BMDP2V) (23) was also applied to the postprandial energy expenditure data. The same grouping factors were used with the repeated factor: EE02, EE23, and EE34. Orthogonal polynomial analysis was also used to test for trends during these three energy expenditure periods. Analysis of covariance (BMDP2V) was also used to analyze the TEF. Covariates in the statistical analysis of energy expenditure and TEF included infant weight (g), intake of the feeding (g), duration of the feeding ( $\mathrm{min}$ ), duration of the calorimetric test ( $\mathrm{min}$ ), time elapsed from the beginning of the feeding to the start of the calorimetric test ( $\mathrm{min}$ ), and time elapsed from the end of the feeding to the start of the calorimetric test (min). Regression analysis (Minitab) (24) was used to relate intake, energy expenditure, and growth. Values are expressed as means and $\mathrm{SD}$.

\section{RESULTS}

Subjects. A description of the 40 subjects who completed the study is presented in Table 1. Mean birth weight, birth length, and gestational age were $3381 \pm 333 \mathrm{~g}, 50.0 \pm 2.2 \mathrm{~cm}$, and $39.8 \pm 0.9 \mathrm{wk}$, respectively. There were no statistically significant differences between feeding and age classifications in terms of birth weight and length, gestational age, gravidity, parity, maternal weight and height, and paternal height. Maternal age $(p<$ $0.001)$ and education $(p<0.002)$ were higher among the breastfeeding mothers.

Feeding histories indicated that the breast-fed infants had received human milk exclusively since birth. Four of the infants classified in the 4-mo formula-fed group had been switched from human milk to formula at $7,14,20$, and $21 \mathrm{~d}$ of life. In the formula-fed group, Enfamil with supplemental iron was consumed by five infants, Enfamil without supplemental iron by five infants, Similac with supplemental iron by six infants, and Similac without supplemental iron by four infants at the time of study. Six of the 4-mo-old formula-fed infants were receiving supplemental foods. Multivitamin supplements were reported to be given to seven of the breast-fed and two of the formula-fed infants. Fluoride supplements were reported to be given to six of the breast-fed and two of the formula-fed infants. None of the infants was reported to be receiving additional iron.

Minor illnesses were reported for eight of the breast-fed and seven of the formula-fed infants between $\mathrm{d} 3$ and 14. Illnesses included colds, fever, constipation, thrush, jaundice, and ear infections. All infants were healthy at the beginning of this study and during the 5-d assessment of food intake and the 24-h milk collection.

Anthropometry. Mean weight, length, weight-for-length ${ }^{2}$, head, chest, and arm circumferences were not statistically different between feeding groups at the time of study (Table 2). An age 
Table 1. Subject characteristics

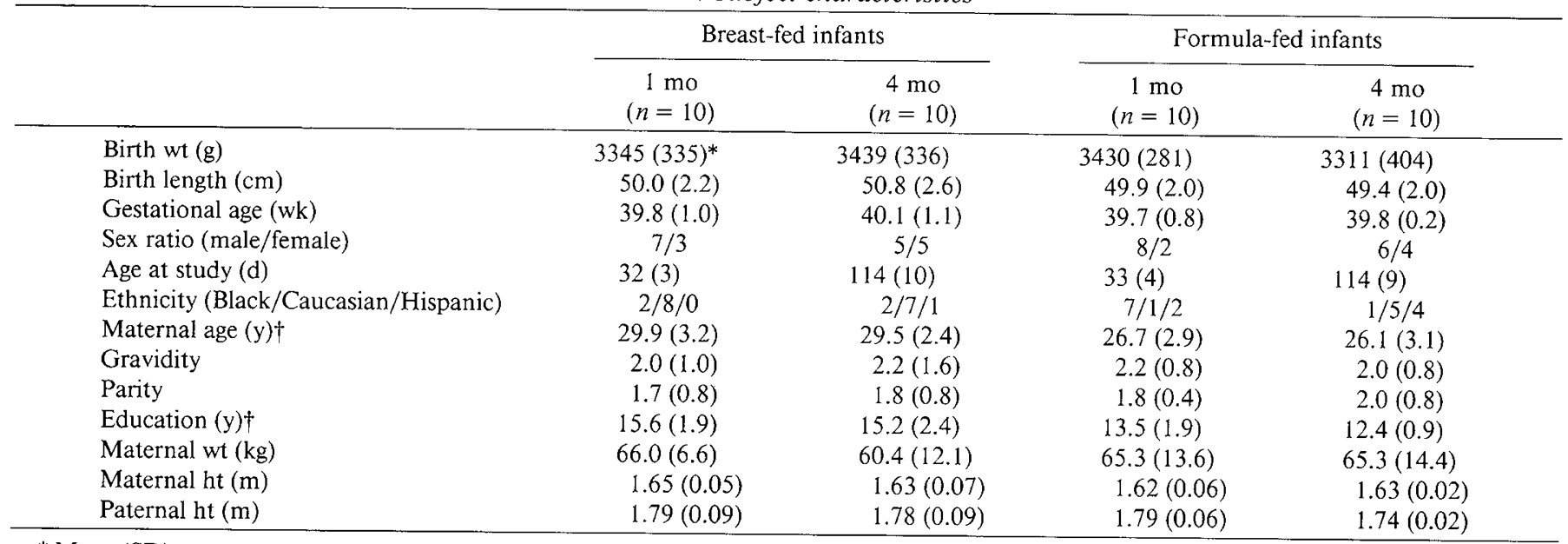

* Mean (SD).

$\dagger p \leq 0.001-0.002$ for feeding effect by analysis of variance.

Table 2. Anthropometric indices of breast-fed and formula-fed infants at 1 and 4 mo of age

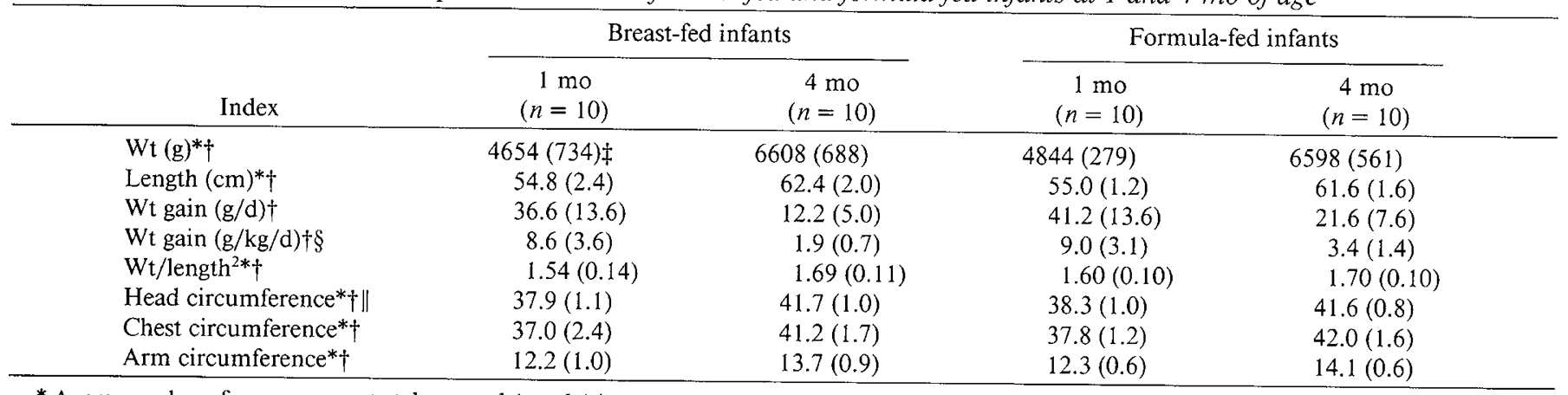

* Average value of measurements taken on $\mathrm{d} 1$ and 14 .

$\dagger p \leq 0.001$ for age effect by analysis of variance.

$\$$ Mean (SD).

$\S p \leq 0.03$ for feeding effect by analysis of variance.

$\| p \leq 0.006$ for sex effect by analysis of variance.

effect $(p<0.001)$ was seen for all of the above indices. A sex effect (male $>$ female; $p<0.006$ ) was observed for head circumference.

Weight gain $(\mathrm{g} / \mathrm{d})$ tended to differ between breast-fed and formula-fed infants $(p<0.06)$. Weight gain $(\mathrm{g} / \mathrm{kg} / \mathrm{d})$ differed between feeding groups $(p<0.027)$.

The NCHS percentile rankings and Z-scores are shown in Table 3. There were no statistically significant differences between feeding groups at birth or at the time of study. The change in percentiles from birth to the time of study at 1 or 4 mo did not differ between feeding groups.

Clinical assessment. Vital signs recorded in the Clinical Research Center were clinically unremarkable. Mean rectal temperature, blood pressure, respiratory rate, and heart rate were $37.3 \pm 0.23^{\circ} \mathrm{C}, 97.8 \pm 8.2 \mathrm{~mm} \mathrm{Hg}, 40 \pm 4$ breaths/min , and 142 \pm 9 beats/min, respectively. No statistically significant differences were demonstrated between feeding groups.

Intake. Foods consumed by the infants during the 5-d observation period at home are tabulated in Table 4 . The breast-fed infants consumed $733 \pm 221 \mathrm{~g} / \mathrm{d}\left(\mathrm{CV}_{\text {subjects }}=30.0 \% ; \mathrm{CV}_{\text {days }}=\right.$ $8.0 \%)$ at $1 \mathrm{mo}$ and $770 \pm 104 \mathrm{~g} / \mathrm{d}\left(\mathrm{CV}_{\text {subjects }}=13.3 \% ; \mathrm{CV}_{\text {days }}=\right.$ $7.8 \%)$ at $4 \mathrm{mo} . \mathrm{CV}_{\text {subjects }}$ reflects the variability between subjects and $\mathrm{CV}_{\text {days }}$ represents the variability between days for individuals. The mean intakes of formula were $856 \pm 131 \mathrm{~g} / \mathrm{d}_{\left(\mathrm{CV}_{\text {subjects }}=\right.}=$ $\left.12.8 \% ; \mathrm{CV}_{\text {days }}=10.6 \%\right)$ at $1 \mathrm{mo}$ and $782 \pm 136 \mathrm{~g} / \mathrm{d}\left(\mathrm{CV}_{\text {subjects }}=\right.$ $\left.16.6 \% ; \mathrm{CV}_{\text {days }}=11.3 \%\right)$ at $4 \mathrm{mo}$. There was no difference between the consumption of Similac and Enfamil. Six of the 4mo-old formula-fed infants received supplemental foods. Supplemental water was given only to the 1-mo-old infants.
The composition of the human milk and formulas is presented in Table 5. The gross energy content of human milk averaged $0.66 \pm 0.06$ and $0.62 \pm 0.08 \mathrm{kcal} / \mathrm{g}$ at 1 and $4 \mathrm{mo}$, respectively. The gross energy concentration of both formulas was $0.67 \pm 0.01$ $\mathrm{kcal} / \mathrm{g}$. Mean energy concentration calculated from the energy equivalents of milk $(5.65 \mathrm{kcal} / \mathrm{g}$ protein, $3.95 \mathrm{kcal} / \mathrm{g}$ lactose, and $9.25 \mathrm{kcal} / \mathrm{g}$ fat $)(25)$ was within $2 \pm 5 \%$ of the value determined by bomb calorimetry. Our analysis of the gross energy content of formula $(0.67 \mathrm{kcal} / \mathrm{g})$ determined by bomb calorimetry was not consistent with the manufacturers' stated value $(0.67-0.68$ $\mathrm{kcal} / \mathrm{g}$ ) for metabolizable energy.

Nutrient intakes of the breast-fed and formula-fed infants calculated from the 5-d home intake records are shown in Table 6 . Energy intake was significantly different between the breastfed and the formula-fed infants at $1 \mathrm{mo}(101 \pm 16$ versus $118 \pm$ $17 \mathrm{kcal} / \mathrm{kg} / \mathrm{d})$ and $4 \mathrm{mo}$ of age $(72 \pm 9$ versus $87 \pm 11 \mathrm{kcal} / \mathrm{kg} /$ d) $(p<0.001)$. Energy intake differed by age $(p<0.001)$ and sex $(p<0.03)$. Energy intakes were higher among the male infants. Supplementation ( $7 \pm 9 \mathrm{kcal} / \mathrm{kg} / \mathrm{d})$ accounted for $8 \pm$ $11 \%$ of the energy intake of the 4-mo-old formula-fed infants. Protein, lactose, and fat intakes $(\mathrm{g} / \mathrm{d})$ were significantly higher among the formula-fed infants $(p<0.003-0.02)$. Expressed on a weight basis, the intake $(\mathrm{g} / \mathrm{kg} / \mathrm{d})$ of these nutrients differed by feeding mode and age $(p<0.003)$.

Milk and energy intakes recorded in the Clinical Research Center did not differ from those recorded at home. Mean energy intakes in the Clinical Research Center were $100 \pm 25$ and $73 \pm$ $11 \mathrm{kcal} / \mathrm{kg} / \mathrm{d}$ for the 1 - and 4-mo-old breast-fed infants, and 
Table 3. NCHS percentiles and Z-scores of breast-fed and formula-fed infants at birth and 1 and 4 mo of age

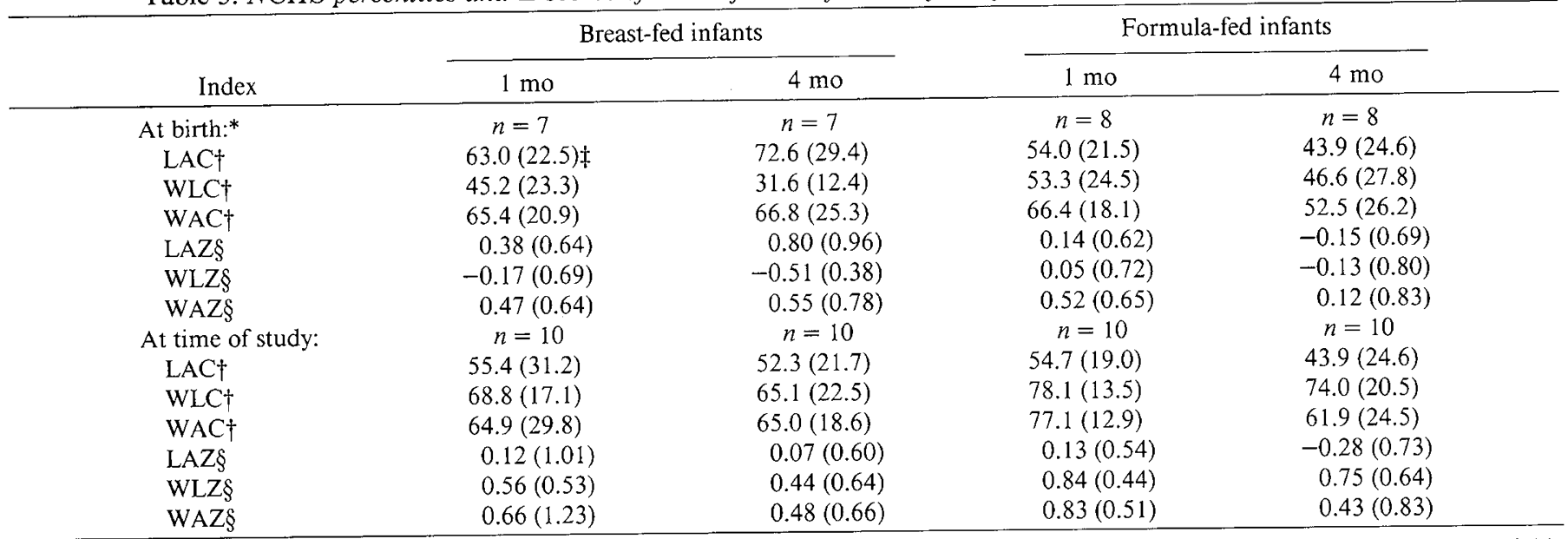

* Values calculated for wt-for-length for 10 of the 40 infants were outside of the range of NCHS values at birth, probably a result of unreliable measurements of length taken from hospital records.

$\dagger$ NCHS (11) percentiles: LAC, length-for-age; WLC, wt-for-length; WAC, wt-for-age.

$\ddagger$ Mean (SD).

$\S$ NCHS (11) Z-scores: LAZ, length-for-age; WLZ, wt-for-length; WAZ, wt-for-age.

Table 4. Intake of breast-fed and formula-fed infants at 1 and 4 mo of age measured over 5 consecutive $d$ at home

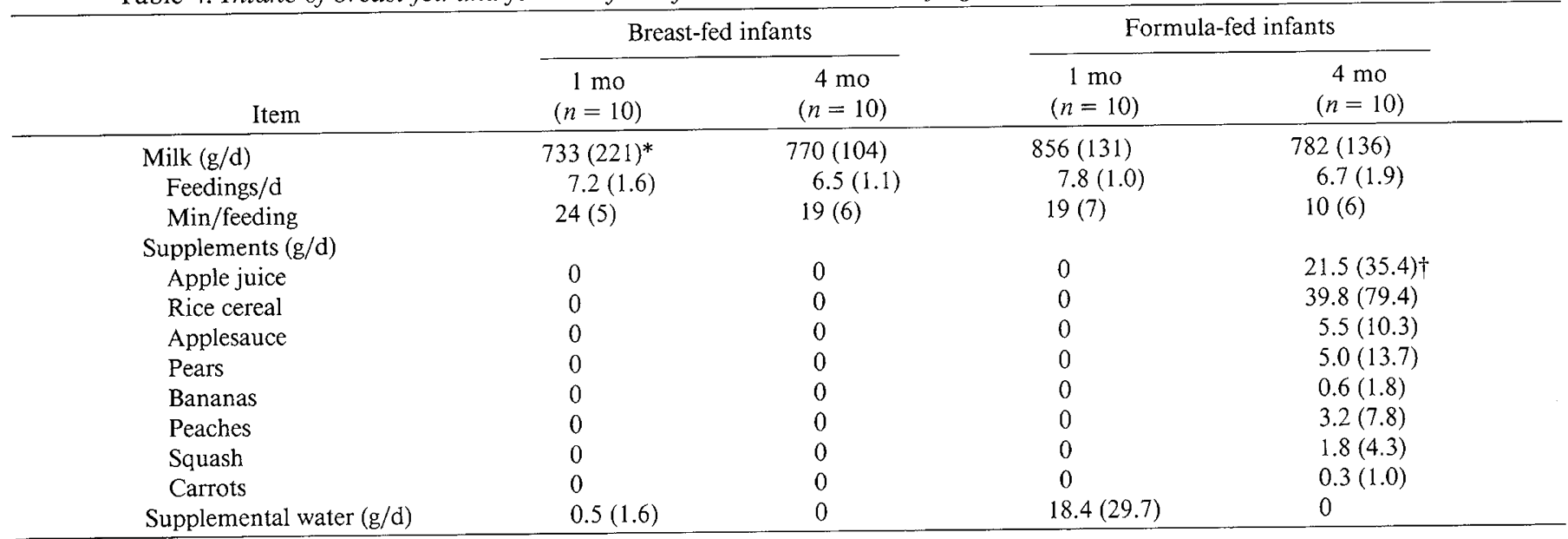

* Mean (SD).

$\dagger$ Supplemental intake averaged over the 10 infants. Items as listed were consumed by three, four, three, two, one, two, two, and one infant, respectively.

Table 5. Milk composition

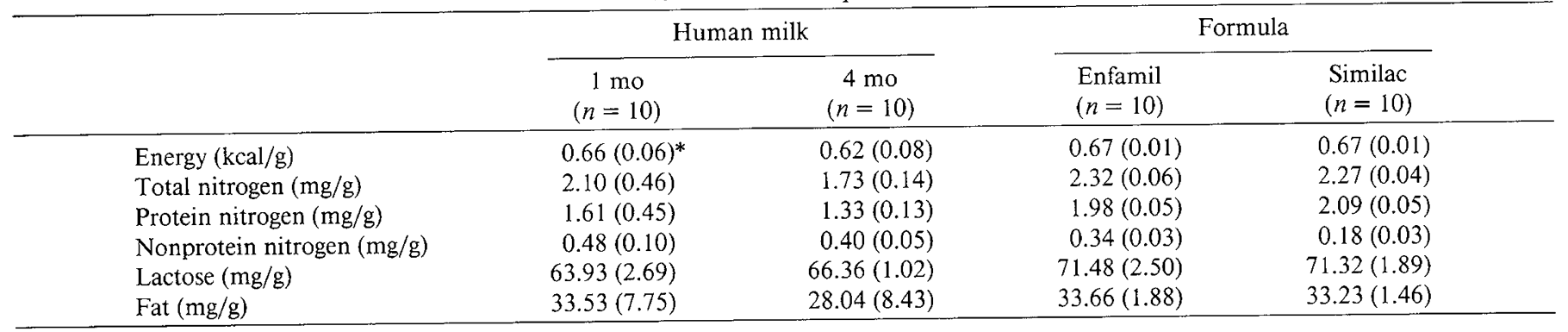

* Mean (SD).

$115 \pm 17$ and $94 \pm 17 \mathrm{kcal} / \mathrm{kg} / \mathrm{d}$ for the 1 - and 4-mo-old formulafed infants, respectively.

Indirect calorimetry. Postprandial energy expenditures have been summarized for 32 completed 4-h calorimetric tests (Table 7). Sample size was reduced to 32 to use BMDP2V analysis of covariance for repeated measures, which requires a complete data set. Eight infants were eliminated from this analysis because they awakened during one of the three time intervals, EE02, EE23, or EE34. Available energy expenditure data for these eight infants, however, were not significantly different from the data of the other infants. In addition, repetition of the analysis of covariance, substituting estimated energy expenditure values for missing data, did not alter the results. Calculation of the missing values used the relative position of each infant's existing data to the mean of the remaining seven.

Analysis of covariance for the time intervals EE02, EE23, and EE34 indicated that the effect of feeding mode on energy expenditure was dependent on age $(p<0.02)$. When infants were 
Table 6. Nutrient intakes of breast-fed and formula-fed infants at 1 and 4 mo of age measured over 5 consecutive $d$ at home

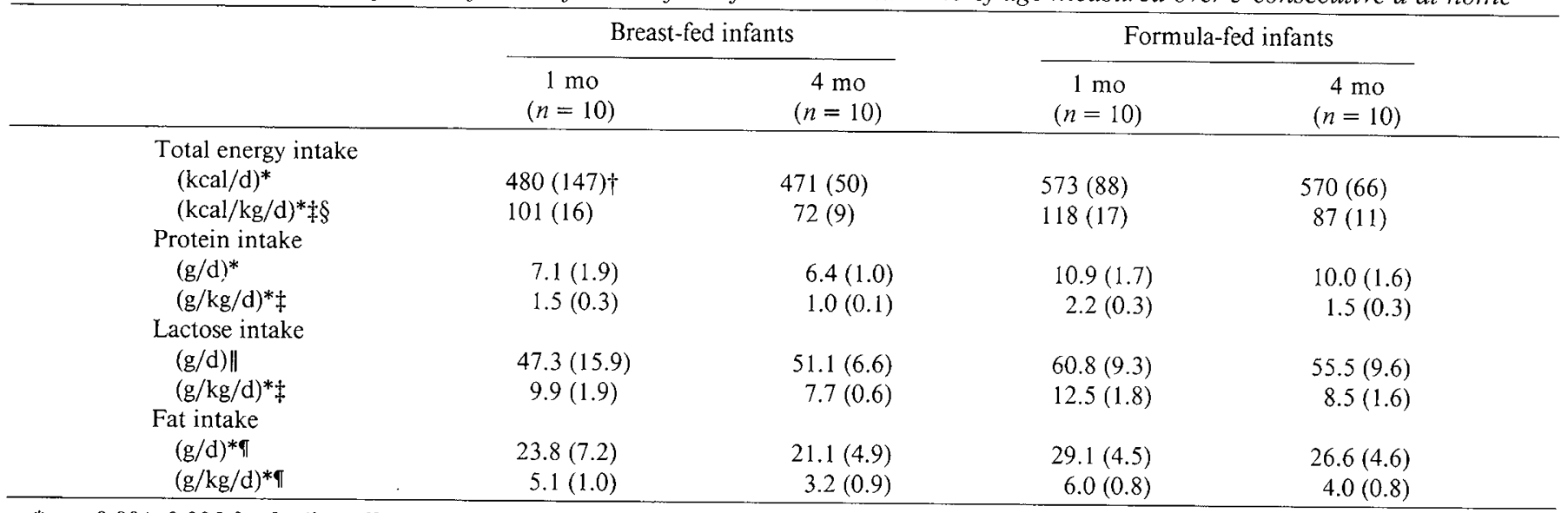

${ }^{*} p \leq 0.001-0.005$ for feeding effect by analysis of variance.

$\dagger$ Mean (SD).

$\ddagger p \leq 0.001$ for age effect by analysis of variance.

$\S p \leq 0.03$ for sex effect by analysis of variance.

$\| p \leq 0.02$ for feeding effect by analysis of variance.

ๆ $p \leq 0.01-0.02$ for age-sex interaction by analysis of variance.

Table 7. Postprandial energy expenditure of breast-fed and formula-fed infants at 1 and 4 mo of age

\begin{tabular}{|c|c|c|c|c|}
\hline & \multicolumn{2}{|c|}{ Breast-fed infants } & \multicolumn{2}{|c|}{ Formula-fed infants } \\
\hline & $\begin{array}{c}1 \text { mo } \\
(n=7)\end{array}$ & $\begin{array}{c}4 \text { mo } \\
(n=9)\end{array}$ & $\begin{array}{c}1 \mathrm{mo} \\
(n=7)\end{array}$ & $\begin{array}{c}4 \text { mo } \\
(n=9)\end{array}$ \\
\hline \multicolumn{5}{|l|}{ Energy expenditure $(\mathrm{kcal} / \mathrm{min})^{*}$} \\
\hline EE02 & $0.183(0.023) \dagger$ & $0.229(0.015)$ & $0.185(0.010)$ & $0.253(0.027)$ \\
\hline EE23 & $0.179(0.019)$ & $0.218(0.018)$ & $0.180(0.014)$ & $0.243(0.023)$ \\
\hline EE34 & $0.175(0.023)$ & $0.220(0.018)$ & $0.180(0.018)$ & $0.244(0.020)$ \\
\hline EE04 & $0.179(0.019)$ & $0.223(0.016)$ & $0.183(0.011)$ & $0.247(0.023)$ \\
\hline \multicolumn{5}{|l|}{ Energy expenditure $(\mathrm{kcal} / \mathrm{kg} / \mathrm{min})^{*}$} \\
\hline $\mathrm{EE} 02$ & $0.039(0.002)$ & $0.035(0.004)$ & $0.040(0.004)$ & $0.040(0.003)$ \\
\hline EE23 & $0.038(0.002)$ & $0.033(0.003)$ & $0.039(0.003)$ & $0.038(0.003)$ \\
\hline EE34 & $0.037(0.003)$ & $0.034(0.003)$ & $0.039(0.004)$ & $0.038(0.002)$ \\
\hline EE04 & $0.038(0.002)$ & $0.034(0.003)$ & $0.040(0.003)$ & $0.038(0.003)$ \\
\hline Mean RQ at 0 to $4 \mathrm{~h}$ postprandial & $0.94(0.02)$ & $0.90(0.05)$ & $0.90(0.06)$ & $0.90(0.05)$ \\
\hline \multicolumn{5}{|l|}{ Covariates } \\
\hline $\mathrm{DF}(\mathrm{min})+$ & $\begin{array}{r}114(42) \\
33(11)\end{array}$ & $108(48)$ & $102(25)$ & $126(45)$ \\
\hline $\mathrm{TBF}(\mathrm{min}) \ddagger$ & $\begin{array}{l}33(11) \\
94(21)\end{array}$ & $26(8)$ & $23(15)$ & $24(16)$ \\
\hline $\mathrm{TFF}(\min ) \ddagger$ & $\begin{array}{l}94(21) \\
61(25)\end{array}$ & $77(24)$ & $86(56)$ & $64(25)$ \\
\hline DT $(\min ) \ddagger$ & $\begin{array}{r}61(25) \\
174(23)\end{array}$ & $50(21)$ & $63(55)$ & $40(21)$ \\
\hline & & $193(23)$ & $183(39)$ & $196(23)$ \\
\hline
\end{tabular}

${ }^{*} p \leq 0.02$ for feeding-age interaction by analysis of variance.

$\dagger$ Mean (SD).

$¥ \mathrm{DF}$, duration of feeding; TBF, time elapsed from beginning of feeding; TFF, time elapsed from finish of feeding; DT, duration of test.

divided on the basis of age, a significant difference in energy expenditure $(\mathrm{kcal} / \mathrm{min})$ between feeding groups was evident only at $4 \mathrm{mo}$ of age $(p<0.01)$. Energy expenditures for the 4-mo-old infants were significantly different between time intervals $(p<$ $0.001)$; there was also evidence of linear $(p<0.001)$ and quadratic $(p<0.002)$ trends. High variability in energy expenditure among the 1-mo-old infants precluded detection of significant effects or trends.

Standardized by infant weight, postprandial energy expenditure values differed between feeding groups only at 4 mo of age. Energy expenditure $(\mathrm{kcal} / \mathrm{kg} / \mathrm{min})$ was significantly higher among the formula-fed infants compared with that among the breast-fed infants $(p<0.01)$. Energy expenditures of the 4-moold infants differed between periods $(p<0.001)$; significant linear and quadratic trends $(p<0.001)$ were demonstrated.

The mean RQ at 0 to $4 \mathrm{~h}$ postprandial did not differ by feeding mode, sex, or age.

SMR and MOEE. The SMR and MOEE of the 40 infants are presented in Table 8. The values for SMR and MOEE (kcal/ min) were significantly lower among the breast-fed infants compared with values for the formula-fed infants $(p<0.005)$. With SMR expressed in terms of body weight, the difference between feeding groups was greater at 4 mo than at 1 mo of age (interaction between feeding mode and age, $p<0.04$ ). MOEE, expressed in terms of body weight, differed significantly between feeding groups $(p<0.005)$. Controlling for weight gain did not eliminate differences in SMR or MOEE observed between breastfed and formula-fed infants. SMR and MOEE were highly correlated $(r=0.92)$. The ratio of MOEE/SMR was $0.90 \pm 0.03$. SMR and MOEE were not related to weight gain, ponderal index, or NCHS rankings.

$T E F$. TEF, analyzed as a function of EE34, SMR, or MOEE, is presented in Table 9. The TEF did not differ by feeding mode, age, or sex. The TEF could not be related to intake preceding the test, duration of the feeding, duration of the calorimetric test, time elapsed from the beginning of the feeding to the start of the calorimetric test, RQ, or weight gain. 
Table 8. SMR and MOEE of breast-fed and formula-fed infants

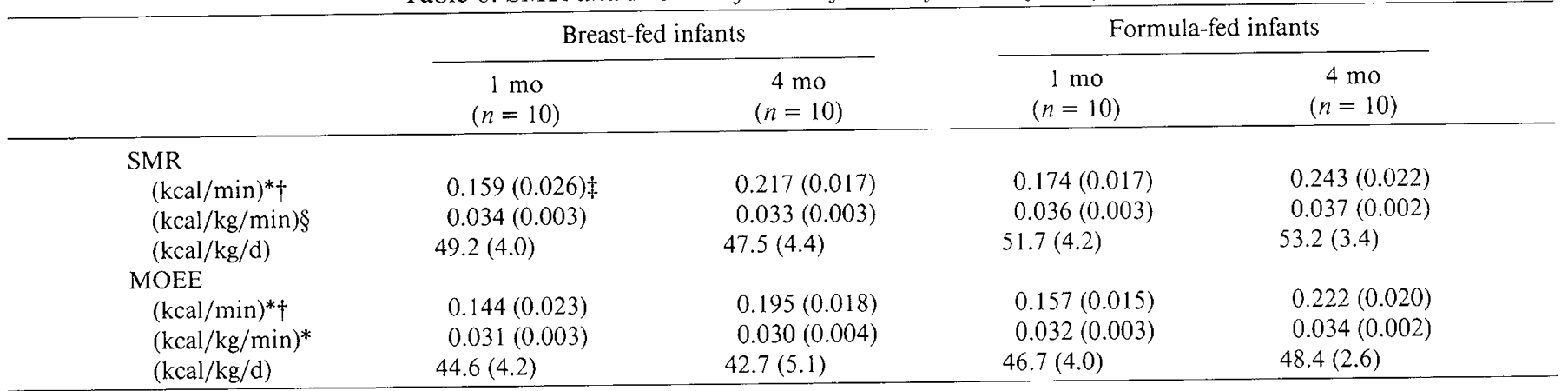

$* p \leq 0.003-0.005$ for feeding effect by analysis of variance.

$\dagger p \leq 0.001$ for age effect by analysis of variance.

\$ Mean (SD).

$\S p \leq 0.04$ for feeding-age interaction by analysis of variance.

Table 9. Thermic effect of feeding of breast-fed and formula-fed infants at 1 and 4 mo of age

\begin{tabular}{cccccc}
\hline & \multicolumn{2}{c}{ Breast-fed infants } & & \multicolumn{2}{c}{ Formula-fed infants } \\
\cline { 2 - 3 } \cline { 5 - 6 } & $\begin{array}{c}1 \mathrm{mo} \\
(n=7)\end{array}$ & $\begin{array}{c}4 \mathrm{mo} \\
(n=9)\end{array}$ & & $\begin{array}{c}1 \\
(n=7)\end{array}$ & $\begin{array}{c}4 \mathrm{mo} \\
(n=9)\end{array}$ \\
\hline TEF:EE34 & $4.2(6.5)^{*}$ & $2.0(2.4)$ & & $2.3(7.2)$ & $1.6(2.7)$ \\
TEF:SMR & $6.2(4.6)$ & $3.0(2.1)$ & & $4.7(6.4)$ & $2.8(2.4)$ \\
TEF:MOEE & $18.0(7.2)$ & $15.0(7.0)$ & & $17.3(8.1)$ & $12.7(3.7)$ \\
\hline
\end{tabular}

* Mean (SD) expressed as a percentage rise in energy expenditure.

IWL. Rate of IWL was monitored for an average of $94 \pm 38$ $\min$ (Table 10). Room temperature and relative humidity ranged from 22 to $26^{\circ} \mathrm{C}$ and 34 to $56 \%$, respectively, during the time of observation. IWL, standardized to body weight, averaged 0.019 $\mathrm{g} / \mathrm{kg} / \mathrm{min}$ and did not differ by feeding, age, or sex classification.
IWL $(\mathrm{g} / \mathrm{kg} / \mathrm{d})$ was positively correlated with $\mathrm{SMR}(\mathrm{kcal} / \mathrm{kg} / \mathrm{d})$ $(r=0.37 ; p<0.05)$ and MOEE $(\mathrm{kcal} / \mathrm{kg} / \mathrm{d})(r=0.30 ; p<0.05)$, but not TDEE.

$T D E E$. Parameters generated by the doubly labeled water method are presented in Table $10 . \mathrm{N}_{\mathrm{H}}$ and $\mathrm{N}_{\mathrm{O}}$ did not differ between feeding groups, but were significantly different between sexes (male $>$ female; $p<0.02)$ and ages $(p<0.001)$. The ratio of $\mathrm{N}_{\mathrm{H}} / \mathrm{N}_{\mathrm{O}}$ did not differ with feeding mode, age, or sex. Daily change in ${ }^{2} \mathrm{H}$ dilution space and ${ }^{18} \mathrm{O}$ dilution space declined with age $(p<0.001)$. The $\mathrm{k}_{\mathrm{H}}$ and $\mathrm{k}_{\mathrm{O}}$ were higher among the younger infants $(p<0.004)$. There was a tendency for $\mathrm{k}_{\mathrm{H}}(p<0.13)$ and $\mathrm{k}_{\mathrm{O}}(p<0.09)$ to be higher among the formula-fed compared with breast-fed infants. The $\mathrm{k}_{\mathrm{H}} / \mathrm{k}_{\mathrm{O}}$ ratio differed only by age $(p<0.001)$. TDEE $(\mathrm{kcal} / \mathrm{d})$ was different between feeding groups $(p<0.02)$, ages $(p<0.001)$, and sexes (male $>$ female; $p<$ $0.02)$. Expressed in terms of body weight, TDEE $(\mathrm{kcal} / \mathrm{kg} / \mathrm{d})$ was different between feeding groups $(p<0.04)$, ages $(p<0.04)$, and

Table 10. Isotope dilution spaces, fractional turnover rates of ${ }^{2} \mathrm{H}$ and ${ }^{18} \mathrm{O}, \mathrm{IWL}$, and TDEE of breast-fed and formula-fed infants at 1 and 4 mo of age

\begin{tabular}{|c|c|c|c|c|}
\hline & \multicolumn{2}{|c|}{ Breast-fed infants } & \multicolumn{2}{|c|}{ Formula-fed infants } \\
\hline & $\begin{array}{c}1 \mathrm{mo} \\
(n=10)\end{array}$ & $\begin{array}{c}4 \text { mo } \\
(n=10)\end{array}$ & $\begin{array}{c}1 \mathrm{mo} \\
(n=10)\end{array}$ & $\begin{array}{c}4 \mathrm{mo} \\
(n=10)\end{array}$ \\
\hline Study interval (d) & $7.0(1.4)^{*}$ & $7.5(0.5)$ & $7.6(0.3)$ & $7.1(0.6)$ \\
\hline $\mathrm{N}_{\mathrm{H}}(\mathrm{g}) \dagger \dagger \S$ & $3144(419)$ & $3781(372)$ & $3135(189)$ & $3911(338)$ \\
\hline $\mathrm{N}_{\mathrm{O}}(\mathrm{g}) \ddagger \S$ & $3107(401)$ & $3669(383)$ & $3060(200)$ & $3824(334)$ \\
\hline $\mathrm{N}_{\mathrm{H}} / \mathrm{N}_{\mathrm{O}}$ & $1.01(0.02)$ & $1.03(0.02)$ & $1.02(0.02)$ & $1.02(0.02)$ \\
\hline $\mathrm{Q}_{\mathrm{H}}(\mathrm{g} / \mathrm{d}) \S$ & $26(10)$ & $7(3)$ & $27(9)$ & $13(5)$ \\
\hline $\mathrm{Q}_{\mathrm{o}}(\mathrm{g} / \mathrm{d}) \S$ & $25(10)$ & $7(3)$ & $26(9)$ & $13(5)$ \\
\hline $\mathrm{k}_{\mathrm{H}}\left(\mathrm{d}^{-1}\right) \S$ & $0.254(0.047)$ & $0.218(0.011)$ & $0.284(0.054)$ & $0.225(0.022)$ \\
\hline $\mathrm{k}_{\mathrm{O}}\left(\mathrm{d}^{-1}\right) \S$ & $0.288(0.050)$ & $0.262(0.013)$ & $0.325(0.060)$ & $0.270(0.020)$ \\
\hline $\mathrm{k}_{\mathrm{H}} / \mathrm{k}_{\mathrm{O}} \oint$ & $0.88(0.02)$ & $0.83(0.01)$ & $0.87(0.01)$ & $0.83(0.02)$ \\
\hline \multicolumn{5}{|l|}{ IWL } \\
\hline$(\mathrm{g} / \mathrm{kg} / \mathrm{min})$ & $0.019(0.005)$ & $0.017(0.003)$ & $0.021(0.002)$ & $0.018(0.003)$ \\
\hline$\left(\%{ }^{\mathrm{r}} \mathrm{H}_{2} \mathrm{O}\right) \S$ & $16.0(4.1)$ & $20.3(3.4)$ & $16.6(2.9)$ & $19.5(3.0)$ \\
\hline \multicolumn{5}{|l|}{ TDEE } \\
\hline$(\mathrm{kcal} / \mathrm{d}) \| \S \ddagger$ & $291(48)$ & $420(49)$ & $316(42)$ & $476(58)$ \\
\hline$\left(\mathrm{kcal} / \mathrm{kg}\right.$ body wt/d) $\| \Psi^{* *}$ & $64(7)$ & $64(8)$ & $67(8)$ & $73(9)$ \\
\hline$\left(\mathrm{kcal} / \mathrm{kg} \mathrm{N}_{\mathrm{H}} / \mathrm{d}\right) \| \S$ & $92(9)$ & $111(11)$ & $101(13)$ & $122(12)$ \\
\hline$(\mathrm{kcal} / \mathrm{kg} \mathrm{N} / \mathrm{d}) \| \S$ & $94(10)$ & $115(11)$ & $103(13)$ & $124(11)$ \\
\hline TDEE/SMR I & $1.28(0.12)$ & $1.34(0.15)$ & $1.26(0.16)$ & $1.36(0.12)$ \\
\hline TDEE/MOEEף & $1.41(0.15)$ & $1.50(0.15)$ & $1.40(0.14)$ & $1.49(0.14)$ \\
\hline
\end{tabular}

* Mean (SD).

$\dagger$ Abbreviations: $\mathrm{Q}_{\mathrm{H}}$ and $\mathrm{Q}_{\mathrm{O}}$, daily changes in ${ }^{2} \mathrm{H}$ and ${ }^{18} \mathrm{O}$ dilution spaces; ${ }^{\mathrm{r}} \mathrm{H}_{2} \mathrm{O}$, total water output.

$\ddagger p \leq 0.01-0.02$ for sex effect by analysis of variance.

$\S p \leq 0.001-0.005$ for age effect by analysis of variance.

$\| p \leq 0.02-0.04$ for feeding effect by analysis of variance.

I $p \leq 0.02-0.04$ for age effect by analysis of variance.

$* * p \leq 0.05$ for sex effect by analysis of variance. 
sexes (male $>$ female; $p<0.05$ ). Standardized by $\mathrm{N}_{\mathrm{H}}$ or $\mathrm{N}_{\mathrm{O}}$, TDEE differed by feeding mode $(p<0.02)$ and age $(p<0.001)$. Controlling for weight gain did not eliminate differences in TDEE observed between feeding groups. TDEE $(\mathrm{kcal} / \mathrm{kg} / \mathrm{d})$ was positively correlated with SMR $(\mathrm{kcal} / \mathrm{kg} / \mathrm{d})(r=0.59 ; p<0.001)$ and MOEE $(\mathrm{kcal} / \mathrm{kg} / \mathrm{d})(r=0.64 ; p<0.001)$. The ratios TDEE/ SMR and TDEE/MOEE differed only by age $(p<0.025)$.

The energy available for activity, derived from the difference between TDEE and SMR, was $13 \pm 6$ and $13 \pm 7 \mathrm{kcal} / \mathrm{kg} / \mathrm{d}$ for the 1 -mo-old, and $16 \pm 6$ and $19 \pm 7 \mathrm{kcal} / \mathrm{kg} / \mathrm{d}$ for the $4-\mathrm{mo}-$ old breast-fed and formula-fed infants, respectively. The energy available for activity did not differ between feeding groups, but did differ by age $(p<0.02)$ and sex (male $>$ female; $p<0.06$ ).

Energy deposition, the difference between metabolizable energy intake and TDEE, was $29 \pm 18$ and $42 \pm 16 \mathrm{kcal} / \mathrm{kg} / \mathrm{d}$ for the 1 -mo-old and $2 \pm 7$ and $7 \pm 13 \mathrm{kcal} / \mathrm{kg} / \mathrm{d}$ for the 4 -mo-old breast-fed and formula-fed infants, respectively. Energy deposition differed by age $(p<0.001)$ and tended to be lower among the breast-fed infants $(p<0.06)$. Energy deposition $(\mathrm{kcal} / \mathrm{kg} / \mathrm{d})$ was positively correlated with energy intake $(\mathrm{kcal} / \mathrm{kg} / \mathrm{d})(r=$ $0.92 ; p<0.001)$ and weight gain $(\mathrm{g} / \mathrm{kg} / \mathrm{d})(r=0.64 ; p<0.001)$.

Multiple regression was used to explore the discrepancy in energy intake observed between breast-fed and formula-fed infants at 1 and 4 mo of age. Energy intake was designated as the dependent variable and feeding group, age, weight gain, TDEE, and SMR as the independent variables; variables were standardized by body weight. The model accounted for $62 \%$ of the variability in energy intake. Feeding group $(p<0.05)$ and age $(p<0.01)$ were the only significant factors. With adjustment for age, weight gain, TDEE, and SMR, the discrepancy in energy intake between feeding groups was reduced from 16 to $12 \mathrm{kcal} /$ $\mathrm{kg} / \mathrm{d}$, but remained significant.

Weight gain $(\mathrm{g} / \mathrm{kg} / \mathrm{d})$ was positively correlated with energy, protein, lactose, and fat intakes $(\mathrm{g} / \mathrm{kg} / \mathrm{d})(r=0.63-0.74 ; p<$ $0.01)$. Weight gain $(\mathrm{g} / \mathrm{kg} / \mathrm{d})$ was not correlated with SMR, MOEE, or TDEE $(\mathrm{kcal} / \mathrm{kg} / \mathrm{d})$.

Positive correlations were observed between energy intake and SMR $(r=0.28, p<0.08)$ and MOEE $(r=0.28 ; p<0.07)$. Energy intake was correlated with IWL $(r=0.38 ; p<0.05)$ and rectal temperature $(r=0.38 ; p<0.05)$. Energy intake was not correlated with TDEE or the energy available for activity. Activity was positively correlated with TDEE $(r=0.84 ; p<0.01)$, but not with SMR, MOEE, or weight gain. Protein, lactose, and fat intakes were not significantly correlated with any parameter of energy expenditure. Neither TDEE nor activity was significantly correlated with the ponderal index or the NCHS rankings. All of the above variables were standardized by body weight.

\section{DISCUSSION}

Significant differences in TDEE, SMR, MOEE, energy deposition, and weight gain demonstrated that key physiologic parameters were affected in early infancy by the mode of feeding. Energy expended in activity and the TEF did not differ between feeding groups. Our findings confirmed previously observed differences in energy intake between breast-fed and formula-fed infants (2-4), and revealed significant differences between the two feeding groups in energy utilization for maintenance and growth. Although body weight and composition did not differ, increased rates of weight gain expected in our previous study (3) were demonstrated. SMR, in contrast to our prior study, MOEE, TDEE, and energy deposition (significant at the 0.06 level) were found to be higher among the formula-fed infants.

Energy intakes of the breast-fed infants were lower than those of the formula-fed infants not only at 4 mo of age, as observed in our previous study (3), but also at 1 mo of age. The testweighing procedure underestimates human milk intake by an amount equal to the weight of IWL during the course of feeding. Based on the measurements of IWL and recorded feeding times, the energy intakes of the breast-fed infants may have been underestimated by $2 \%$. Differences in the macronutrient composition of human milk and formula, combined with disparate levels of milk intake, resulted in significant differences in protein, lactose, and fat intake. Although our study was focused on differences in energy intake, we recognize that intakes of macronutrients, minerals, vitamins, and specific proteins differ substantially between feeding groups and may also influence energy utilization by infants. Because of the marked differences in the composition of human milk and formula, inferences regarding a cause and effect relationship between energy intake and energy utilization cannot be made.

Higher rates of energy deposition among the formula-fed infants $(p \leq 0.06)$ were congruent with their higher weight velocities. (Our estimations of energy deposition are highly dependent upon the assumption of equal digestibility constants for breast-fed and formula-fed infants.) Despite higher rates of weight gain, differences in body weights, lengths, NCHS percentiles, or changes in NCHS percentiles between birth and the time of study were not seen between feeding groups. Different patterns of growth before the time of study might explain these seemingly incongruous results. Neither the ponderal indices nor the $N_{H}$ and $N_{O}$ dilution spaces were indicative of body compositional differences between breast-fed and formula-fed infants. The energy cost of growth of these infants was computed for a separate publication (26) and found not to differ by feeding mode, age, or sex; our ability to detect significant differences, however, was limited by individual variation and experimental error. Persistence of different rates of weight gain would likely result in different body sizes as reported for older breast-fed and formulafed infants (27). Similarly, if disparate levels of energy intake and weight gain were to continue into later infancy, differences in body composition might also emerge. It was also apparent that weight gain was not inversely related to energy expenditure as might be anticipated. The formula-fed infants disposed of surfeit energy by augmented expenditure and deposition.

Differences in SMR and MOEE between feeding groups suggested an adaptive response to different levels of energy intake. Although there is disagreement among reports in the literature (28-33), evidence suggests a reduction in overall metabolic activity in severely malnourished children $(28,29)$. Basal energy expenditure was shown to have increased rapidly upon recovery from malnutrition and was positively correlated with energy intake (28). Although our SMR observations may be on this continuum, they never approached the nadir of $38 \mathrm{kcal} / \mathrm{kg} / \mathrm{d}$ reported for malnourished infants. In addition, breast-fed infants, unlike malnourished infants, do not increase their energy intake when given the opportunity. The ad libitum addition of solid foods to the diets of exclusively breast-fed infants neither augmented their energy intakes nor reversed the decline in their NCHS weight-for-age percentiles observed during exclusive breastfeeding (34).

Nevertheless, the higher SMR and MOEE of the formula-fed infants may reflect differences in growth rate, body composition, facultative thermogenesis, or metabolic costs associated with the nutrient balance in formulas. The first two possibilities are not supported by the findings of our present study; neither SMR nor MOEE was related to weight gain. ${ }^{2} \mathrm{H}$ and ${ }^{18} \mathrm{O}$ dilution spaces were similar between feeding groups. No physiologic or biochemical basis for the dissipation of surfeit energy has been documented convincingly in humans. The latter explanation of nutrient imbalance is conjecture with no evidence from human studies.

Our ability to detect statistically significant differences in energy intake at 1 and $4 \mathrm{mo}$, SMR, and weight gain may have been the result of limited sample size in our previous study (3). Therefore, we combined results from the present and former studies to reconcile seeming inconsistencies (35). By analysis of variance $(n=105)$, energy intake $(\mathrm{kcal} / \mathrm{kg} / \mathrm{d}, p \leq 0.001)$, SMR $(\mathrm{kcal} / \mathrm{kg} / \mathrm{d}, p \leq 0.015)$, and MOEE $(\mathrm{kcal} / \mathrm{kg} / \mathrm{d}, p \leq 0.002)$ were significantly lower among the breast-fed infants. Weight gain $(\mathrm{g} /$ 
d) was significantly different between feeding groups at the $p \leq$ 0.055 level; normalization by body weight tended to diminish the difference in weight gain seen between feeding groups ( $p \leq$ 0.11 ).

Although varying levels of energy intake might be expected to influence TEF (36), we were unable to detect differences between feeding groups in the TEF relative to SMR or MOEE. The magnitude of the TEF, however, was difficult to resolve from our present data because SMR and MOEE were measured under nonfasting conditions and, therefore, encompassed a residual component of TEF.

Postprandial energy expenditures (EE02, EE23, and EE34) differed between feeding groups only at 4 mo of age, although we controlled several factors that theoretically could have influenced energy expenditure. Among the 4-mo-old infants, energy expenditure clearly declined over the $4 \mathrm{~h}$ of observation, and there was evidence that energy expenditure plateaued between the $3 \mathrm{rd}$ and $4 \mathrm{th} \mathrm{h}$. The decline in postprandial energy expenditure may reflect decreasing expenditure for digestion, absorption, or synthetic activities associated with nutrient assimilation. High variability in energy expenditure precluded detection of distinct patterns among the 1-mo-old infants. They awakened more frequently than the 4-mo-old infants before completion of the 4$\mathrm{h}$ test; six of the eight infants who failed to complete the test were 1 mo old.

The measurements of TDEE should be considered from both methodologic and biologic standpoints. Although the few validation trials of the doubly labeled water method in infants demonstrated close agreement $[0.3 \pm 2.6 \%(5) ; 1.6 \pm 6.2 \%(6)]$ with indirect calorimetry, controversy persists as to which model and correction factors should be used to compute TDEE (37). In our present study, we assumed that the change in pool size was a linear function of time; had growth been exponential, the error introduced would have been less than $2 \%$ (37). Contrary to the assumption that ${ }^{2} \mathrm{H}$ and ${ }^{18} \mathrm{O}$ exchange solely with water and $\mathrm{CO}_{2}$, the isotopes exchange with nonaqueous body constituents and the extent of exchange is different for the respective isotopes. Because we suspect the interindividual variation in $\mathrm{N}_{\mathrm{H}} / \mathrm{N}_{\mathrm{O}}$ might have a physiologic basis related to body fatness, we chose to use the actual dilution spaces of ${ }^{2} \mathrm{H}$ and ${ }^{18} \mathrm{O}$. The $\mathrm{N}_{\mathrm{H}} / \mathrm{N}_{\mathrm{O}}$ ratio was not related to the rate of weight gain. In this data set, we did observe four $\mathrm{N}_{\mathrm{H}} / \mathrm{N}_{\mathrm{O}}$ values less than $1(0.988-0.999)$. Although we agree that these values are not physiologic, they are within the analytical, sampling, and biologic errors of the method. Higher rates of irreversible isotope incorporation, particularly of ${ }^{2} \mathrm{H}$, might be expected in the more rapidly growing infants. Either the differential effect or isotope accretion in tissue is minor or the growth rate of these infants is relatively slow compared, for instance, with that of preterm infants (5) and animals (38).

Isotope fractionation is another issue that must be addressed in implementing the doubly labeled water method. The proportion of total water loss that undergoes fractionation during evaporation across epithelial surfaces was based on integrated weight loss per unit time and averaged $18 \%$ of total water flux, a value similar to those derived by Roberts et al. (16\%) (5) and Jones et al. $(18 \%)(6)$ using alternative methodologies. Measurements based on integrated weight loss per unit time can give rise to an overestimation of true IWL, because insensible weight loss = IWL $+\mathrm{r}_{\mathrm{CO}_{2}}+\mathrm{r}_{\mathrm{O}_{2}}$ (39).

In our present study, the average RQ was 0.91 and IWL would have been overestimated by approximately $18 \%$ had it not been offset by environmental water influx (40). Measurements based on integrated weight loss per unit time determine net IWL and therefore underestimate true unidirectional water efflux, the component of interest. At $24^{\circ} \mathrm{C}$ and $45 \%$ relative humidity, the average conditions under which the measurements were made in the hospital, we might have underestimated IWL by $25 \%$ (40). Throughout the duration of the doubly labeled water experiment, however, the infants were exposed to variable, unpredictable climatic conditions inside and outside of their homes. Because the errors in measurements based on integrated weight loss per unit time are opposite in direction, but unpredictable in magnitude, we chose not to correct IWL. Calculation of the rate of fractionated water loss based on $\mathrm{r}_{\mathrm{CO}_{2}}$ as proposed by Jones et al. (6) yielded values that were approximately $3 \%$ higher than our measured IWL; this difference would introduce only an approximate $1 \%$ error in TDEE.

In the conversion of $\mathrm{CO}_{2}$ production to TDEE, the RQ must be measured or assumed. We assigned the mean RQ measured $4 \mathrm{~h}$ postprandially; because of the frequent feeding of infants (every 3 to $4 \mathrm{~h}$ ), we believed this RQ to be representative of their metabolic state. If indirect calorimetry is not available, the food quotient corrected for digestibility and tissue deposition may be used (41). The food quotient computed for the 1-mo-old breastfed and formula-fed infants was 0.93 and 0.90 , respectively, and 0.87 and 0.86 for the 4-mo-old breast-fed and formula-fed infants, respectively. Use of the food quotient would have introduced a 0 to $4 \%$ error in TDEE.

TDEE $(\mathrm{kcal} / \mathrm{d})$, measured by the doubly labeled water method, differed between breast-fed and formula-fed infants. Standardization of TDEE by body weight or isotope dilution spaces, indicators of fat-free body mass, did not alter this finding. Although some systematic errors introduced in the computation of TDEE by the doubly labeled water method may persist, it is unlikely that the basic assumptions underlying the doubly labeled water method and the correction factors used should differ between breast-fed and formula-fed infants. The $\mathrm{N}_{\mathrm{H}} / \mathrm{N}_{\mathrm{O}}$ ratio, $\mathrm{RQ}$, and IWL at a given age did not differ between feeding groups. Our values for TDEE are similar or slightly lower than values reported for infants at similar ages. Davies et al. (42) recently reported mean values of 63 and $66 \mathrm{kcal} / \mathrm{kg} / \mathrm{d}$ for 40 term infants studied longitudinally at 1.5 and $3 \mathrm{mo}$ of age, respectively. Lucas et al. (7) cited $72 \mathrm{kcal} / \mathrm{kg} / \mathrm{d}$ for 11 -wk-old breast-fed British infants. Roberts et al. (8) reported mean values ranging from 61 to $77 \mathrm{kcal} / \mathrm{kg} / \mathrm{d}$ for 3 -mo-old infants and did not find a significant human milk versus formula effect. VasquezVelasquez (9) found no appreciable trend over a wide range of ages ( 2 to $29 \mathrm{mo}$ ); the mean TDEE of these Gambian infants was $82 \mathrm{kcal} / \mathrm{kg} / \mathrm{d}$.

The ratios TDEE/SMR and TDEE/MOEE were nearly identical for breast-fed and formula-fed infants at a given age. Accepting the factorial approach, an estimate of the energy available for activity was computed and found not to differ between feeding groups. The activity component increased with age, but was not influenced by energy intakes observed in our study. One of the adaptations to inadequate energy intake is a reduction in discretionary physical activity; the energy intakes that we observed may have been above any critical threshold for energy conservation. At this stage of development, physical activity is largely reflexive and may be spared. An estimate of the energy available for activity, however, provides no indication of infant behavior. Optimal neurobehavioral development is dependent upon the infant's ability to interact with and explore the environment. Complementary studies of infant behavior and activity patterns are needed to characterize our quantitative observations of energy expenditure.

The factorial approach, however, may not be appropriate in infant studies, because it cannot be assumed that SMR represents a constant metabolic baseline throughout the day. Under the conditions of measurement, the SMR may have been influenced by fluctuations in biosynthesis and sympathetic activity, residual TEF, and spontaneous activity during sleep.

Our findings explain in part the discrepancy in energy intake observed between breast-fed and formula-fed infants. Energy intake was positively correlated with weight gain, energy deposition, SMR, and MOEE, but not with TDEE or activity. Higher energy intakes in the formula-fed infants were associated with higher rates of weight gain, SMR, MOEE, TDEE, and energy deposition. The discrepancy in energy intake observed between feeding groups, however, was not totally accounted for by differ- 
ences in energy expenditure and weight gain; energy digestibility and the composition of the newly synthesized tissues may differ between feeding groups. Adaptations to varying levels of energy intake during infancy appear to be mediated through growth and basal-energy-requiring processes.

Acknowledgments. The authors thank the women who willingly participated in this study and acknowledge the contributions of Carolyn Heinz, Cora Rafanan, Anne Adolph, Nitesh Mehta, Mary Thotathuchery, Suman Vaidya, Lucinda Lee Clarke, and Marisol Llaurador for technical assistance and Angela Cavese, Roseland E. Klein, Jerry Eastman, and Cynthia Fedrick for secretarial and editorial support. We also are grateful to Ross Laboratories and Mead Johnson and Company for their formula donations.

\section{REFERENCES}

1. Waterlow JC, Alleyne GAO 1971 Protein malnutrition in children: advances in knowledge in the last ten years. Adv Protein Chem 25:117-235

2. Whitehead RG, Paul AA 1985 Human lactation, infant feeding and growth secular trends. In: Gracey M, Falkner F (eds) Nutritional Needs and Assessment of Normal Growth. Nestle Nutrition Workshop Series, Vol 7. Raven Press, New York, pp 85-122

3. Butte NF, Smith EO, Garza C 1990 Energy utilization of human milk-fed and formula-fed infants. Am J Clin Nutr 51:350-358

4. Dewey KG, Heinig MJ, Nommsen NA, Lonnerdal B 1989 Dietary guidelines for infants. Lancet 1:504

5. Roberts SB, Coward WA, Schlingenseipen K-H, Nohria V, Lucas A 1986 Comparison of the doubly labeled water $\left({ }^{2} \mathrm{H}_{2}{ }^{18} \mathrm{O}\right)$ method with indirect calorimetry and nutrient-balance study for simultaneous determination of energy expenditure, water intake and metabolizable energy intake in preterm infants. Am J Clin Nutr 44:315-322

6. Jones PJH, Winthrop AL, Schoeller DA, Swyer PR, Smith J, Filler RM, Heim T 1987 Validation of doubly labeled water for assessing energy expenditure in infants. Pediatr Res 21:242-246

7. Lucas A, Ewing G, Roberts SB, Coward WA 1987 How much energy does the breast-fed infant consume and expend? Br Med J 295:75-77

8. Roberts SB, Savage J, Coward WA, Chew B, Lucas A 1988 Energy expenditure and intake in infants born to lean and overweight mothers. $N$ Engl $J$ Med 318:461-466

9. Vasquez-Velasquez L 1988 Energy expenditure and physical activity of malnourished and Gambian infants. Proc Nutr Soc 47:233-239

10. Fjeld CR, Schoeller DA, Brown KH 1989 A new model for predicting energy requirements of children during catch-up growth developed using doubly labeled water. Pediatr Res 25:503-508

11. National Center for Health Statistics 1977 NCHS growth curves for children birth-18 years. DHEW publication no (PHS)78-1650, Washington, DC

12. Schoeller DA, Leitch CA, Brown C 1986 Doubly labeled water method: in vivo oxygen and hydrogen isotope fractionation. Am J Physiol 251:R1137-R1143

13. Butte NF, Garza C, Smith EO, Nichols BL 1984 Human milk intake and growth in exclusively breast-fed infants. J Pediatr 104:187-195

14. Jeejeebhoy KN, Ahmad S, Kozak G 1970 Determination of fecal fats contain ing both MCT, LCT, and fatty acids. Clin Biochem 3:157-163

15. Jequier $E 1981$ Long term measurement of energy expenditure in man: direct or indirect calorimetry? In: Bray G (ed) Recent Advances in Obesity Research III. Proceedings of the 2nd International Congress on Obesity. Newman Publishing, London, pp 130-135

16. de V Weir JB 1949 New methods for calculating metabolic rate with special reference to protein metabolism. J Physiol 109:1-9
17. Wong WW, Lee LS, Klein PD 1987 Deuterium and oxygen-18 measurements on microliter samples of urine, plasma, saliva, and human milk. Am J Clin Nutr 45:905-913

18. Baertschi P 1976 Absolute ${ }^{18} \mathrm{O}$ content of standard mean ocean water. Earth Planet Sci Lett 31:341-344

19. De Wit JC, Van Der Straaten CM, Mook WG 1980 Determination of the absolute hydrogen isotopic ratio of V-SMOW and SLAP. Geostand Newslett $4: 33-36$

20. Wong WW, Cochran WJ, Klish WJ, Smith EO, Lee LS, Klein PD 1988 In vivo isotope-fractionation factors and the measurement of deuterium- and oxygen-18-dilution spaces from plasma, urine, saliva, respiratory water vapor, and carbon dioxide. Am J Clin Nutr 47:1-6

21. Southgate DAT, Barrett IM 1966 The intake and excretion of calorific constituents of milk by babies. Br J Nutr 20:363-372

22. SPSS-X version 3.01988 SPSS, Inc., Chicago

23. Dixon WJ (ed) 1983 BMDP, Biomedical computer programs. University of California Press, Berkeley, CA

24. Minitab version 6.1 1988 Minitab, Inc., State College, PA

25. Watt BK, Merril AL 1963 Composition of foods. Agricultural handbook no. 8. Agricultural Research Services USDA, Washington, DC, p 160

26. Butte NF, Wong WW, Garza C 1989 Energy cost of growth during infancy. Proc Nutr Soc 48:303-312

27. Whitehead RG, Paul AA 1984 Growth charts and the assessment of infant feeding practices in the western world and in developing countries. Early Hum Dev 9:187-207

28. Parra A, Garza C, Garza Y, Saravia JL, Hazelwood CF, Nichols BL 1973 Changes in growth hormone, insulin, and thyroxine values, and in energy metabolism of marasmic infants. J Pediatr 82:133-142

29. Brooke OG, Cocks T, March Y 1974 Resting metabolic rate in malnourished babies in relation to total body potassium. Acta Paediatr Scand 63:817-825

30. Levine SZ, Wilson JR, Gottschall G 1928 The respiratory metabolism in infancy and in childhood. VIII. The respiratory exchange in marasmus: basal metabolism. Am J Dis Child 35:615-630

31. Fleming GB, Hutchison HS 1924 A study of the metabolism in the undernourished infant. Q J Med 17:339-357

32. Montgomery RD 1962 Changes in the basal metabolic rate of the malnourished infant and their relation to body composition. J Clin Invest 41:1653-1663

33. Krieger I, Whitten CF 1969 Energy metabolism in infants with growth failure due to maternal deprivation, undernutrition, or causes unknown. J Pediatr 75:374-379

34. Stuff JE, Nichols BL 1989 Nutrient intake and growth performance of older breast-fed infants. J Pediatr 115:959-968

35. Butte NF, Wong WW, Garza C, Klein PD 1990 Adequacy of human milk for meeting energy requirements during early infancy. In: Atkinson SA, Hanson LA, Chandra RK (eds) Breastfeeding, Nutrition, Infection and Infant Growth in Developed and Emerging Countries. ARTS Biomedical Publishers and Distributors, Newfoundland, Canada, pp 103-116

36. Rothwell NJ, Stock MJ 1983 Diet-induced thermogenesis. In: Girardier L Stock MJ (eds) Mammalian Thermogenesis. Chapman and Hall, New York, pp 208-233

37. Schoeller DA 1988 Measurement of energy expenditure in free-living humans by using doubly labeled water. J Nutr 1 18:1278-1289

38. Nagy KA $1980 \mathrm{CO}_{2}$ production in animals: analysis of potential errors in the doubly labeled water method. Am J Physiol 238:R466-R473

39. Doyle LW, Sinclair JC 1982 Insensible water loss in newborn infants. Clin Perinatol 9:453-482

40. Schoeller DA, Fjeld CR 1986 Measurement of human-milk consumption by deuterium oxide kinetics. In: Filer LJ, Fomon SJ (eds) The Breast-fed Infant: A Model for Performance. Report of the 91 st Ross Conference on Pediatric Research. Ross Laboratories, Columbus, OH, pp 13-23

41. Black AE, Prentice AM, Coward WA 1986 Use of food quotients to predict respiratory quotients for the doubly labeled water method for measuring energy expenditure. Hum Nutr Clin Nutr 40C:381-391

42. Davies PSW, Ewing G, Lucas A 1989 Energy expenditure in early infancy. Br J Nutr 62:621-629 